\title{
Basic Reproduction Number of Tuberculosis Spread Model in Lamongan With DOTS Strategy
}

\author{
Aris Alfan', Fitroh Resmi' ${ }^{2}$, Nihaya Alivia C. Dewi. ${ }^{3}$ \\ 1,2,3 Mathematics Departement, Billfath University, Indonesia \\ 19aris.alfan@billfath.ac.id, ${ }^{2}$ fitroh.resmi@billfath.ac.id, ${ }^{3}$ nihaya@billfath.ac.id
}

\begin{abstract}
Article History:

Received : 17-12-2020

Revised : 02-04-2021

Accepted : 03-04-2021

Online : :16-04-2021

\section{Keyword:}

Tuberculosis Model; DOTS ;

Model SEITR;

Basic Reproduction

Number $R_{0}$;

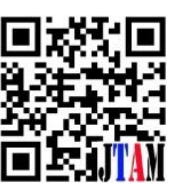

Tuberculosis (TB) will be a serious threat if not handled quickly and appropriately. The relatively long treatment in time and the high risk of death is a challenge in controlling the spread of this disease. The DOTS (Directly Observed Treatment Short-course) strategy is considered capable of controlling the spread of TB because of the high success rate, reaching 91\%. The mathematical model of the spread of TB has been widely studied to determine the potential for the spread of this disease in an area. The purpose of this study is to build a model of tuberculosis spread in Lamongan to determine the rate of its spread and to predict whether it will be endemic or not. Using disease spread mathematical model type SEITR, this research has examined based on 2018 and 2019 data from the Lamongan health office then simulates the result. The research begins with the construction of the model followed by a stability analysis of the model by determining the basic reproduction number $\left(\boldsymbol{R}_{\mathbf{0}}\right)$, which is simulated after the parameter approach was carried out. From the simulation results, the result shows that $\boldsymbol{R}_{\mathbf{0}}=\mathbf{0 . 1 1 4 7}$ means that TB will not endemic in Lamongan. Besides, the results of the effect of parameter $\boldsymbol{\omega}$ on $\boldsymbol{I}(\boldsymbol{t})$ were obtained, which concluded that seeking and treating active TB alone would only reduce infected individuals but not reduce the length of time TB spread. Identification of the effect of parameter $\boldsymbol{\varphi}$ on $\boldsymbol{I}(\boldsymbol{t})$ has also been carried out which results in the conclusion that more treatment for susceptible individuals, in addition to reducing the number of infected individuals, will also reduce the length of time TB spreads in that area. This result will be a good suggestion for the government to deal faster with tuberculosis transmission.
\end{abstract}

\section{doi Crossref}

https://doi.org/10.31764/jtam.v5i1.3696

\section{(c) (i) (2)}

This is an open access article under the CC-BY-SA license

\section{A. INTRODUCTION}

Tuberculosis (TB) is a disease caused by infection with the bacteria Mycobacterium tuberculosis which attacks and damages human tissues. TB usually attacks not only the lungs, but also the bones, lymph nodes, central nerve system, heart, and other organs (Dirjen P2\&PL Kementerian Kesehatan RI, 2011).

Latent TB infection is a type of tuberculosis that often affects patients. in which the TB bacteria are "sleeping" or not yet clinically active. TB bacteria will be active and begin to show symptoms after a certain period of time, several weeks or even years, depending on the patient's health condition and endurance. Direct contact with TB sufferers will have the potential to "wake up" the TB bacteria that are in a person. Patients who suffer from tuberculosis, if not treated immediately, will have the potential to "infect" this disease to ten to fifteen people every year(Rifki Taufik et al., 2015).

The easy transmission of this disease raises concerns about an explosion in patients suffering from this disease if it is not handled immediately. One of the difficulties in handling 
this disease is the relatively long recovery time, which is around 6-24 months regularly (Abdul Halim, 2013). Therefore, serious handling is needed to prevent this disease become an epidemic.

According to WHO, one-third of the world's population has been infected with tuberculosis bacteria, and every second there is one person infected with tuberculosis. The Global TB Report by WHO in 2019 stated that Indonesia was in third place with the highest TB in the world after China and India. Therefore, the government, through Permenkes Number 67 of 2016, has set a national TB control target, namely elimination by 2035 and free TBC by 2050 . Elimination of TB means that there are only 1 TB cases per 1 million population (Kementerian Kesehatan RI, 2018).

In Lamongan district, TB has become a top priority disease to be eliminated considering that until 2017, this disease was one of the most sufferers, namely 2237 cases (BPS Kabupaten Lamongan, 2018). Therefore, Lamongan Lamongan tries to find and treat TB sufferers as early as possible through 33 health centers and 8 hospitals (Lamongan Health Office, 2020). Tuberculosis patient examiners are provided to detect whether someone has TB disease and have also been provided in several health centers in Lamongan. In fact, Lamongan district became one of the 19 recipients of the Coverage and Successful Tuberculosis (TB) Treatment award by the Director-General of Disease Prevention and Control (P2P) of the Indonesian Ministry of Health in 2019 (ACEH, 2019). To handle the spread of TB, in the early 1990s WHO internationally recommended the DOTS (Directly Observed Treatment Short-course) method. This method is considered successful in controlling the spread of TB disease because it has a fairly high success rate, reaching 91\% (Dirjen P2\&PL Kementerian Kesehatan RI, 2011).

A mathematical model can be used to predict how much the potential spread of this infectious disease. The mathematical model of infectious diseases has been studied by many people for a long time especially in tuberculosis elimination, as research has been carried out (Marks et al., 2020) (Matteelli et al., 2017)(Narula et al., 2016) (Melnichenko \& Romanyukha, 2009)(D. Okuonghae \& Korobeinikov, 2007), etc. The mathematical model that discusses the prediction of the spread of TB was first introduced in 1960. In subsequent developments, it has involved other mathematical sciences such as optimal control (Sarini, 2012)(Hattaf et al., 2009)(Zuhri et al., 2020), Differential Equation Systems, and dynamic systems. The journal entitled "Dynamical Models of Tuberculosis and Their Applications" written by Carlos Castillo was also written in 2004 discussing many kinds of dynamics of the TB model(Castillo-chavez, 2013). Research on other models of disease transmission is also being discussed for different approaches.

The purpose of this study is to build a model of tuberculosis spread in Lamongan to determine the rate of its spread and to predict whether it will be endemic or not. In this study, a mathematical model for the spread of TB will be applied in Lamongan area which had implemented the DOTS strategy based on available data in Lamongan Health Office. This research is expected to help the government and society in dealing with the spread of TB disease.

\section{B. METHODS}

This research is in the form of a literature study using data from the health department to conduct a simulation. The research begins with constructing a mathematical model of the spread of tuberculosis and then continues with a model analysis. The Model analysis contains the investigation of a fixed point and its stability by finding the basic reproduction number. Furthermore, data processing is carried out to obtain the required parameters. From the resulting parameters, a model simulation can be created that produces a graphical display which will then be interpreted. In the simulation, several scenarios will also be made to see their effect on the simulation results so that they can produce conclusions or suggestions that can be applied. 
The mathematical model to be used in this study is in the type of a SEITR. SEITR stands for Susceptible (potentially infected population), Exposed (individuals who have been infected but not yet active TB bacteria), Infected (individuals with active and also transmit TB), Treatment (individuals who are undergoing TB treatment but are no longer infectious), and Recovered (individuals who have been declared cured and have finished treatment by medical staff). These five variables are assumed to affect the transmission of TB. From the relations between these variables, a mathematical model will be formed which will then be solved and simulated.

\section{RESULT AND DISCUSSION}

\section{Model Construction}

Using the SEITR model means dividing the existing population $(N)$ into 5 parts. Mathematically it can be written as,

$$
N(t)=S(t)+E(t)+I(t)+T(t)+R(t)
$$

this means that it is assumed that no other disease or disaster happens and just TB significantly reduces the population. SEITR in this study following the following scheme,

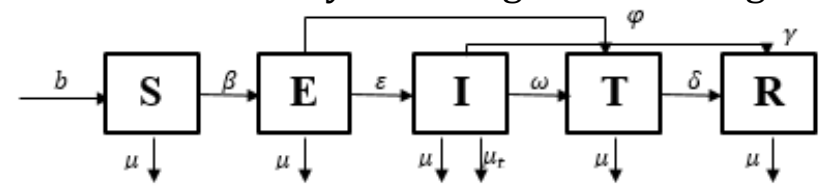

\section{Potentially infected population (S)}

It is a population that is still free from TB bacteria and has never interacted with active TB sufferers. This population will increase if there is birth and will decrease if there is death. This population also decreases when there is an interaction between the $\mathrm{S}$ and I population which makes it a potential entry into the exposed population. Population movement into or out of the designated area will also increase and decrease this population, but in this case, population movement is assumed to be non-existent. Mathematically this explanation can be written as,

\section{Exposed / latent population $(E)$}

$$
\frac{d S}{d t}=b-\beta S I-\mu S,
$$

This population increases due to the interaction between population S and I which has the potential to make it an exposed population. The decline in this population is not only when there is natural death but also when symptoms of TB infection appear in latent individuals. The active TB bacteria is due to decreased body immunity. Treatment of latent individuals as a form of prevention will also reduce this population. Mathematically it can be written,

\section{Population infected (I)}

$$
\frac{d E}{d t}=\beta S I-(\varepsilon+\mu+\varphi) E,
$$

The infected population increases from exposed individuals who have symptoms of infection by TB bacteria which indicates that TB bacteria are starting to be active. While the reduction in this population occurs when there is healing naturally or through treatment. Death naturally or from the disease also reduces this infected population.

$$
\frac{d I}{d t}=\varepsilon E-\left(\omega+\gamma+\mu+\mu_{t}\right) I
$$




\section{Treatment population $(T)$}

The population comes from population I who can no longer transmit TB. The treatment that is being undertaken may not stop until it is completely declared free from TB by medical personnel. The treatment of latent individuals will add to this population. The decline in this population is not only caused by natural death but also when treatment patients are declared cured by medical personnel.

\section{Population recovered $(R)$}

$$
\frac{d T}{d t}=\varphi E+\omega I-(\delta+\mu) T
$$

Population healing can come from natural healing and healing through medication. The only thing that makes this population decline is natural mortality. In this case, it is assumed that individuals who have recovered have gained immunity and are no longer exposed to TB.

$$
\frac{d R}{d t}=\gamma I+\delta T-\mu R
$$

From equations (1) - (5) a mathematical model is obtained,

$$
\left\{\begin{array}{l}
\frac{d S}{d t}=b-\beta S I-\mu S \\
\frac{d E}{d t}=\beta S I-(\varepsilon+\mu+\varphi) E \\
\frac{d I}{d t}=\varepsilon E-\left(\omega+\gamma+\mu+\mu_{t}\right) I \\
\frac{d T}{d t}=\varphi E+\omega I-(\delta+\mu) T \\
\frac{d R}{d t}=\gamma I+\delta T-\mu R
\end{array}\right.
$$

Thus the variables and parameters used in this model are,

Table 1. Variables and parameters in the SEITR model

\begin{tabular}{|c|l|}
\hline $\begin{array}{c}\text { Variables/ } \\
\text { parameters }\end{array}$ & \multicolumn{1}{c|}{ Description } \\
\hline$S(t)$ & Number of susceptible at time $\mathrm{t}$ \\
\hline$E(t)$ & Number of TB latent at time $\mathrm{t}$ \\
\hline$I(t)$ & Number of TB infected at time $\mathrm{t}$ \\
\hline$T(t)$ & Number of individuals got treated at time $\mathrm{t}$ \\
\hline$R(t)$ & Number of recover from TB at time $\mathrm{t}$ \\
\hline$b$ & Recruitment rate \\
\hline$\beta$ & Chances of an individual being infected by TB \\
\hline$\varepsilon$ & Rate of TB latent becoming active TB individuals \\
\hline$\varphi$ & Rate of TB latent got treated \\
\hline$\gamma$ & Natural healing rate \\
\hline$\omega$ & Rate of TB active got treated \\
\hline$\delta$ & Chances of individuals recovery after DOTS treatment \\
\hline$\mu$ & Natural death rate \\
\hline$\mu_{t}$ & Death rate from TB \\
\hline
\end{tabular}

\section{Model Analysis}

\section{a. Fixed Point and Basic Reproduction Number $\left(\boldsymbol{R}_{\mathbf{0}}\right)$}

The fixed point of the model can be obtained if $\frac{d S}{d t}=\frac{d E}{d t}=\frac{d I}{d t}=\frac{d T}{d t}=\frac{d R}{d t}=0$ satisfied. From equation (1) it is obtained, 


$$
\left\{\begin{array}{cl}
0=b-\beta S I-\mu S & \rightarrow S=\frac{b}{\beta I+\mu} \\
0=\beta S I-(\varepsilon+\mu+\varphi) E & \rightarrow E=\frac{\beta S I}{\varepsilon+\mu+\varphi} \\
0=\varepsilon E-\left(\omega+\gamma+\mu+\mu_{t}\right) I & \rightarrow I=\frac{\varepsilon E}{\omega+\gamma+\mu+\mu_{t}} \\
0=\varphi E+\omega I-(\delta+\mu) T & \rightarrow T=\frac{\varphi E+\omega I}{(\delta+\mu)} \\
0=\gamma I+\delta T-\mu R & \rightarrow R=\frac{\gamma I+\delta T}{\mu}
\end{array}\right.
$$

By substituting equation (7), two fixed points are obtained,

$$
P_{1}=\left(\frac{b}{\mu}, 0,0,0,0\right) \text { and } P_{2}=\left(S^{*}, E^{*}, I^{*}, T^{*}, R^{*}\right)
$$

Where,

$$
\begin{aligned}
& S^{*}=\frac{(\varepsilon+\mu+\varphi)\left(\omega+\gamma+\mu+\mu_{t}\right)}{\beta \varepsilon} ; E^{*}=\frac{b}{(\varepsilon+\mu+\varphi)}-\frac{\mu\left(\omega+\gamma+\mu+\mu_{t}\right)}{\beta \varepsilon} ; I^{*}=\frac{b \varepsilon}{(\varepsilon+\mu+\varphi)\left(\omega+\gamma+\mu+\mu_{t}\right)}-\frac{\mu}{\beta} \\
& T^{*}=\frac{b \varepsilon}{\beta(\varepsilon+\mu+\varphi)\left(\omega+\gamma+\mu+\mu_{t}\right)(\delta+\mu)}-\frac{\omega \mu}{\beta(\delta+\mu)} ; R^{*}=\frac{b \varepsilon(\gamma(\delta+\mu)+\delta \omega)}{\mu(\varepsilon+\mu+\varphi)\left(\omega+\gamma+\mu+\mu_{t}\right)(\delta+\mu)}-\frac{\gamma}{\beta}-\frac{\delta \omega}{\beta(\delta+\mu)}
\end{aligned}
$$

$P_{1}$ represents a fixed point with no TB infection of $I=0$ so $P_{1}$ was not used in this case. Therefore in $P_{2}$, the $I^{*}>0$ must apply,

$$
\begin{gathered}
\frac{b \varepsilon}{(\varepsilon+\mu+\varphi)\left(\omega+\gamma+\mu+\mu_{t}\right)}-\frac{\mu}{\beta}>0 \\
\frac{b \varepsilon}{(\varepsilon+\mu+\varphi)\left(\omega+\gamma+\mu+\mu_{t}\right)}>\frac{\mu}{\beta} \\
\frac{b \beta \varepsilon}{\mu(\varepsilon+\mu+\varphi)\left(\omega+\gamma+\mu+\mu_{t}\right)}>1
\end{gathered}
$$

The inequality (8) becomes a condition for equilibrium for endemic occurrence. The lefthand side of the inequality (8) is also commonly referred to as the basic reproduction number $\left(R_{0}\right)$ which shows the level of spread of an infectious disease in a certain area (Imran et al., 2020).

$$
R_{0}=\frac{b \beta \varepsilon}{\mu(\varepsilon+\mu+\varphi)\left(\omega+\gamma+\mu+\mu_{t}\right)}
$$

If $R_{0} \leq 1$, then for $t \rightarrow \infty$ this disease will not become epidemic and will gradually disappear. Meanwhile, if $R_{0}>1$ then this disease will endemic. Furthermore, it will be investigated whether the two fixed points $P_{1}$ and $P_{2}$ are stable or not.

\section{b. Fixed Point Stability}

To know the stability of a fixed point, it can be found through the system jacobian matrix at a fixed point. The jacobian matrix of system (6) is,

$$
\boldsymbol{J}=\left(\begin{array}{ccccr}
-\beta I-\mu & 0 & -\beta S & 0 & 0 \\
\beta I & -(\varepsilon+\mu+\varphi) & \beta S & 0 & 0 \\
0 & \varepsilon & -X & 0 & 0 \\
0 & \varphi & \omega & -\delta-\mu & 0 \\
0 & 0 & \gamma & \delta & -\mu
\end{array}\right)
$$

With $X=\omega+\gamma+\mu+\mu_{t}$. The jacobian matrix at $P_{1}$ is, 


$$
J\left(P_{1}\right)=\left(\begin{array}{ccccr}
-\beta I-\mu & 0 & -\frac{\beta b}{\mu} & 0 & 0 \\
\beta I & -(\varepsilon+\mu+\varphi) & \frac{\beta b}{\mu} & 0 & 0 \\
0 & \varepsilon & -X & 0 & 0 \\
0 & \varphi & \omega & -\delta-\mu & 0 \\
0 & 0 & \gamma & \delta & -\mu
\end{array}\right)
$$

From $J\left(P_{1}\right)$ it can be obtained the eigenvalues, $\lambda_{3}=\lambda_{4}=-\mu, \lambda_{5}=-(\delta+\mu)$ and

$$
\lambda_{1,2}=-\frac{1}{2}(\varepsilon+\mu+\varphi+X) \pm \frac{1}{2} \sqrt{(\varepsilon+\mu+\varphi+X)^{2}-4\left((\varepsilon+\mu+\varphi) X-\frac{\beta b \varepsilon}{\mu}\right)} .
$$

Since all parameters are positive it is clear that $\lambda_{2,3,4,5}<0$. Given the form of $R_{0}$ in equation (9), $\lambda_{1}$ can be written as,

$$
\lambda_{1}=-\frac{1}{2}(\varepsilon+\mu+\varphi+X)+\frac{1}{2} \sqrt{(\varepsilon+\mu+\varphi+X)^{2}-4(\varepsilon+\mu+\varphi) X\left(1-R_{0}\right)}
$$

It is clear that if $R_{0}<1$ then $\lambda_{1}<0$ whereas if $R_{0}>1$ then $\lambda_{1}>0$. This means that the fixed point $P_{1}$ will be stable if $R_{0}<0$ and becomes unstable when $R_{0}>1$. Next we investigate the fixed point $P_{2}$,

$$
J\left(P_{2}\right)=\left(\begin{array}{ccccc}
-\frac{\beta b \varepsilon}{(\varepsilon+\mu+\varphi) X} & 0 & -\frac{(\varepsilon+\mu+\varphi) X}{\varepsilon} & 0 & 0 \\
\frac{\beta b \varepsilon}{(\varepsilon+\mu+\varphi) X}-\mu & -(\varepsilon+\mu+\varphi) & \frac{(\varepsilon+\mu+\varphi) X}{\varepsilon} & 0 & 0 \\
0 & \varepsilon & -X & 0 & 0 \\
0 & \varphi & \omega & -\delta-\mu & 0 \\
0 & 0 & \gamma & \delta & -\mu
\end{array}\right)
$$

Using the Routh-Hurwitz criterion, the results show that the fixed point $P_{2}$ will be locally asymptotically stable if $R_{0}>1$.

\section{Simulation and discussion}

To simulate the TB dispersion SEITR model (6), parameters are needed. Parameters were obtained by processing data from Lamongan district health office and other necessary sources. Simulations were carried out using Maple software. Furthermore, simulations are carried out with variations in several parameters to see the effect of a parameter on the spread of TB disease in this Lamongan. The data used are 2018 and 2019 so that $t(0)=2017$. The initial conditions used in this case were obtained from data from Lamongan Health Office and the Central Bureau of Statistics (BPS), namely $S(0)=1.287 .272 ; E(0)=67.380 ; I(0)=T(0)=$ $2.246, R(0)=2.168$. The number of people identified with active TB is the same as people who are undergoing treatment because it is assumed that all patients are following treatment regularly. The following parameters are used in the simulation and their sources (Table 2).

Table 2. Parameters used in simulation

\begin{tabular}{|c|c|l|}
\hline Parameters & $\begin{array}{c}\text { Estimated } \\
\text { value }\end{array}$ & \multicolumn{1}{c|}{ Source } \\
\hline$b$ & 0,014 & (Badan Pusat Statistik, 2013) \\
\hline$\beta$ & 0,15 & assumption \\
\hline$\varepsilon$ & 0,1 & Depkes RI, in (Imran et al., 2020) \\
\hline$\gamma$ & 0,03 & assumption \\
\hline$\omega$ & 0,98 & Data of Public Health Office of Lamongan \\
\hline$\delta$ & 0,91 & Kemenkes 2011, in (Ramadhan et al., 2012) \\
\hline$\varphi$ & 0,0 & Data of Public Health Office of Lamongan \\
\hline
\end{tabular}




\begin{tabular}{|c|c|l|}
\hline$\mu$ & 0,0086 & (Badan Pusat Statistik, 2013) \\
\hline$\mu_{t}$ & 0,025 & Data of Public Health Office of Lamongan \\
\hline
\end{tabular}

Thus we get the value of the basic reproduction number $R_{0}=0.1147<0$. This means that TB disease in Lamongan is not endemic.

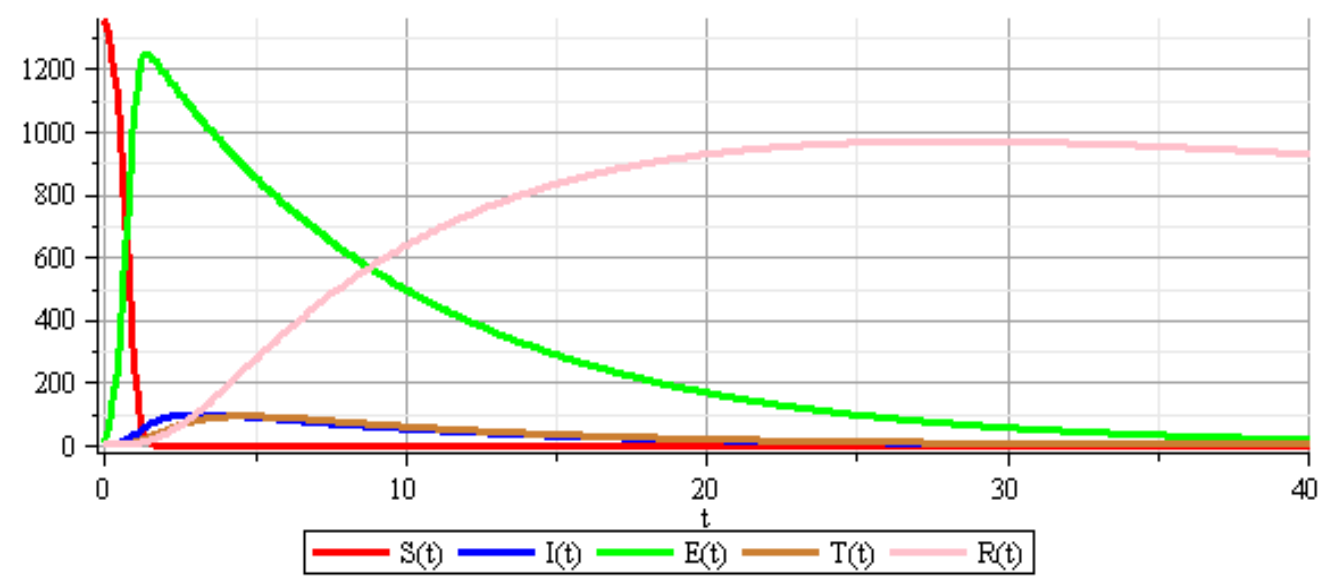

Figure 1. Graph of TB spread in Lamongan

Where the vertical axis shows the population in thousands and the horizontal axis shows the time in years. From Figure 1, it can be seen that the population decreased dramatically in the first two years. The population becomes latent due to interacting with sufferers in proportion to the reduction in the population $S(t)$. With the success of the DOTS program, the cure rate is much higher than the rate of transmission. This can happen if an active TB patient is found and treated immediately. Given that active TB patients will transmit the disease for several weeks after treatment is started. The decline in the number of latent individuals was slowly followed by an increase in the number of individuals who were declared cured.

Figure 2 shows the number of active TB individuals will increase in 2-3 years and then slowly decrease until the number of infected individuals is around 55-65 years after 2017.

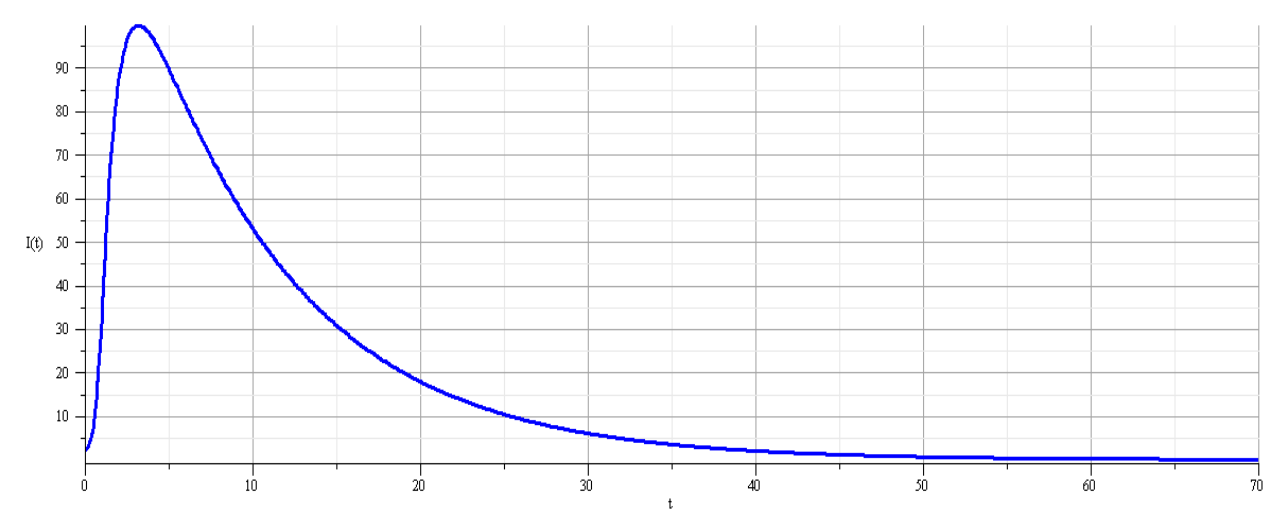

Figure 2. graph of TB-infected individuals in years

In order to keep things from getting worse than this prediction, we will look at the consequences of shifting some parameters. In Figure 3, it can be seen that if the parameter $\omega$ is getting smaller, the number of infected individuals will increase with a significant difference even though it does not reduce the period of infection spread. $\omega=0.7$ means that 7 out of 10 people with active TB are undergoing DOTS treatment, so finding active TB sufferers and then treating them regularly is very important. Lamongan Regency has a value of $\omega=0.98$ which is a good achievement that needs to be maintained. 


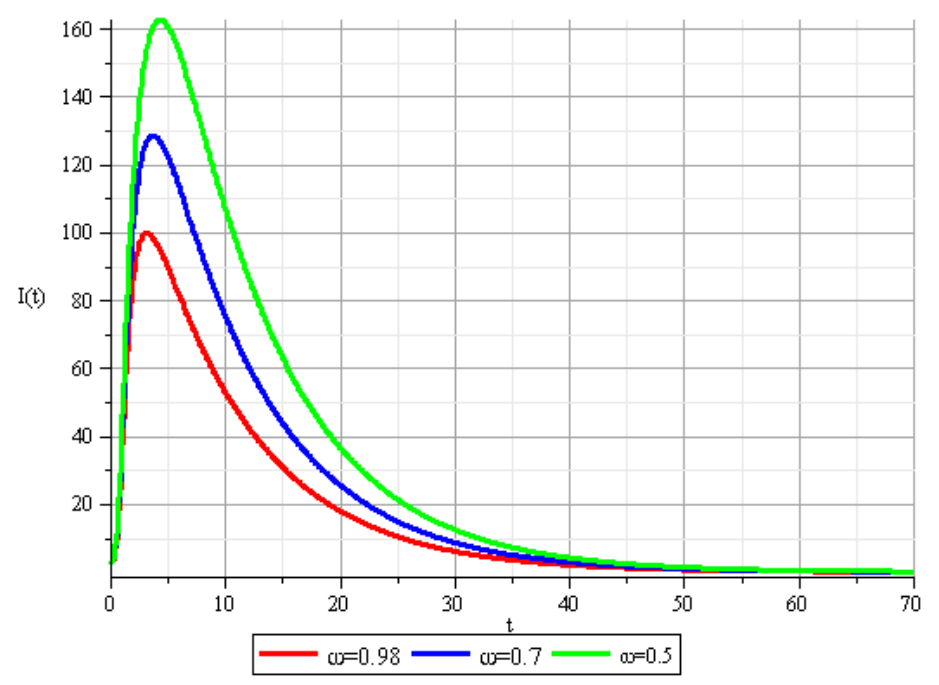

Figure 3. Graph $I(t)$ with variation of the parameter $\omega$

Furthermore, the parameter variation $\varphi$ will be carried out. In Figure 4, it can be seen that changes in the parameter value of $\varphi$ can result in a reduction in the number of infected individuals as well as reducing the period of spread of this disease. $\varphi=0.1$ means that 1 in 10 latent individuals are following TB treatment regularly. This means that treatment of latent individuals also needs to be implemented to immediately succeed in the TB-free program.

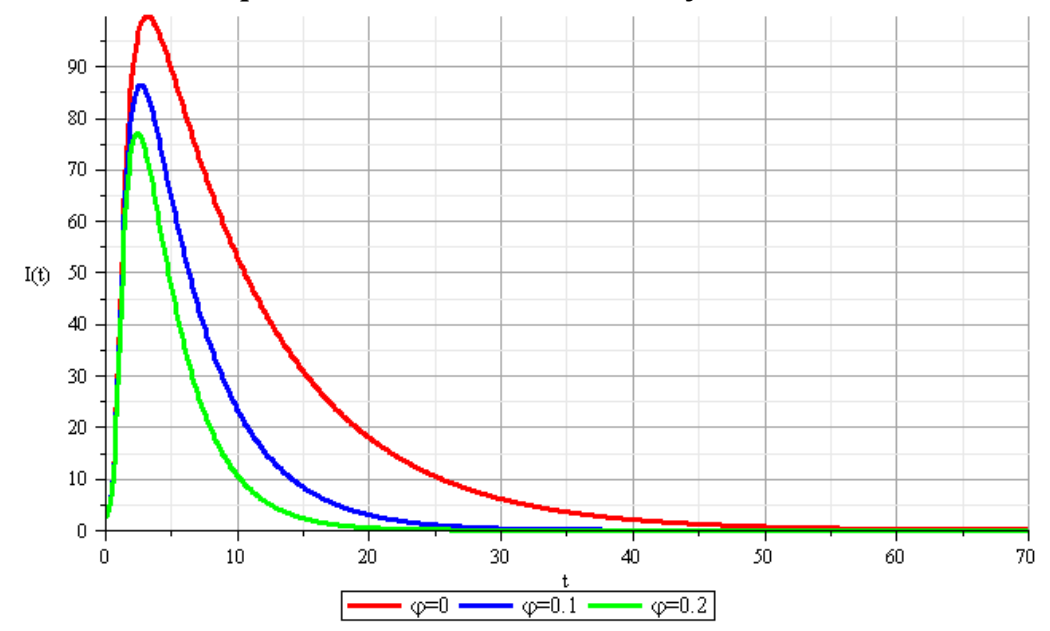

Figure 4. Graph $I(t)$ with variation of the parameter $\varphi$

These results are in line with research on scenarios for TB elimination, Treatment of Latent Tuberculosis Infection (TLTBI) (Tasillo et al., 2017)(Daniel Okuonghae \& Ikhimwin, 2016).

\section{CONCLUSION AND SUGGESTIONS}

From the discussion, it can be concluded that with the current condition, Tuberculosis will not be endemic in Lamongan. It can be seen from the value of the basic reproduction number less than one, $R_{-} 0=0.1147$ Conditions and efforts made in the context of controlling and treating TB need to be maintained so that it does not get worse. From the variation of several parameters, it was found that the smaller value of $\omega$ the more it increases the number of TB sufferers but did not accelerate the spread of TB. Meanwhile, if the parameter $\varphi$ gets bigger, besides it can reducing the number of TB sufferers, it also reduces the period of spreading TB so that the disease can disappear immediately. Therefore, in order to accelerate TB-free programs, it is necessary to take steps to treat latent individuals before they actually become infected with active TB. Related research can use another type of mathematical model to 
approach this problem. In addition, research to reduce the assumptions used also needs to solve in order to obtain a similar model with the real problem.

\section{ACKNOWLEDGEMENT}

This research was supported by KEMENRISTEK-BRIN through national competitive research program - PDP schemes. The writer also say thank you to Lamongan Health Office (Dinas Kesehatan Lamongan) who has support us by supply the required data.

\section{REFERENCES}

Abdul Halim, N. (2013). Tuberculosis Model: A Mathematical Analysis. In University of Malaya (Vol. 66, Issue 1997).

ACEH, M. K. B. (2019). Banda Aceh Raih Capaian Tertinggi Penanganan Tuberkulosis SeIndonesia. http://infopublik.id/kategori/nusantara/389327/banda-aceh-raih-capaiantertinggi-penanganan-tuberkulosis-se-indonesia?video=

Badan Pusat Statistik. (2013). Proyeksi Penduduk Indonesia 2010-2035. In Badan Pusat Statistika, Jakarta-Indonesia.

BPS Kabupaten Lamongan. (2018). Kabupaten Lamongan dalam Angka 2018. Https://Lamongankab.Bps.Go.Id/.

Castillo-chavez, C. (2013). Dynamical models of tuberculosis and applications. CBMS-NSF Regional Conference Series in Applied Mathematics, 1(84), 191-217.

Dirjen P2\&PL Kementerian Kesehatan RI. (2011). Terobosan Menuju Akses Universal, Strategi Nasional Pengendalian TB di Indonesia 2010-2014. Stop TB, 3. http://www.searo.who.int/indonesia/topics/tb/stranas_tb-2010-2014.pdf

Hattaf, K., Rachik, M., Saadi, S., Tabit, Y., \& Yousfi, N. (2009). Exogenous Reinfection. 3(5), 231240.

Imran, R., Pranata, W., \& Ismail, S. (2020). Model Matematika SEIT pada Penyebaran Penyakit Tuberculosis Resistensi Primer.1,1-11. https://doi.org/10.31219/osf.io/er95a

Kementerian Kesehatan RI. (2018). InfoDatin Tuberculosis. Kementerian Kesehatan RI, 1. https://www.depkes.go.id/article/view/18030500005/waspadai-peningkatanpenyakit-

menular.html\%0Ahttp://www.depkes.go.id/article/view/17070700004/programindonesia-sehat-dengan-pendekatan-keluarga.html

Marks, S. M., Dowdy, D. W., Menzies, N. A., Shete, P. B., Salomon, J. A., Parriott, A., Shrestha, S., Flood, J., \& Hill, A. N. (2020). Policy Implications of Mathematical Modeling of Latent Tuberculosis Infection Testing and Treatment Strategies to Accelerate Tuberculosis Elimination. Public Health Reports, 135(1_suppl), 38S-43S. https://doi.org/10.1177/0033354920912710

Matteelli, A., Sulis, G., Capone, S., D’Ambrosio, L., Migliori, G. B., \& Getahun, H. (2017). Tuberculosis elimination and the challenge of latent tuberculosis. In Presse Medicale (Vol. 46, Issue 2, pp. e13-e21). Elsevier Masson SAS. https://doi.org/10.1016/j.lpm.2017.01.015

Melnichenko, A., \& Romanyukha, A. A. (2009). A model of tuberculosis epidemiology: Data analysis and estimation of parameters. Mathematical Models and Computer Simulations, 1(4), 428-444. https://doi.org/10.1134/S2070048209040024

Narula, P., Piratla, V., Bansal, A., Azad, S., \& Lio, P. (2016). Parameter estimation of tuberculosis transmission model using Ensemble Kalman filter across Indian states and union territories. Infection, Disease and Health, 21(4), 184-191. https://doi.org/10.1016/j.idh.2016.11.001

Okuonghae, D., \& Korobeinikov, A. (2007). Dynamics of tuberculosis: The effect of direct observation therapy strategy (DOTS) in Nigeria. Mathematical Modelling of Natural 
Phenomena, 2(1), 113-128. https://doi.org/10.1051/mmnp:2008013

Okuonghae, Daniel, \& Ikhimwin, B. O. (2016). Dynamics of a mathematical model for tuberculosis with variability in susceptibility and disease progressions due to difference in awareness level. In Frontiers in Microbiology (Vol. 6, Issue JAN). https://doi.org/10.3389/fmicb.2015.01530

Ramadhan, M. R., Waluya, S. B., \& Kharis, M. (2012). UNNES Journal of Mathematics. Ujm, 1(2252), 125-130.

Rifki Taufik, M., Lestari, D., \& Wijayanti Septiarini, T. (2015). Mathematical Model for Vaccinated Tuberculosis Disease with VEIT Model. International Journal of Modeling and Optimization, 5(3), 192-197. https://doi.org/10.7763/ijmo.2015.v5.460

Sarini, N. K. M. (2012). Universitas Indonesia Universitas Indonesia Jakarta. Fmipa Ui, 1-95.

Tasillo, A., Salomon, J. A., Trikalinos, T. A., Robert Horsburgh Jr, C., Marks, S. M., \& Linas, B. P. (2017). Cost-effectiveness of Testing and Treatment for Latent Tuberculosis Infection in Residents Born Outside the United States With and Without Medical Comorbidities in a Simulation Model Supplemental content. JAMA Intern Med, 177(12), 1755-1764. https://doi.org/10.1001/jamainternmed.2017.3941

Zuhri, Z., Hamid, A., Subchan, ., \& Rofiki, I. (2020). Optimal Control of Exogenous Reinfection Prevention and Treatment on a Tuberculosis Model. 235-239. https://doi.org/10.5220/0008904702350239 